ECCOMAS Proceedia
COMPDYN 2021

$8^{\text {th }}$ ECCOMAS Thematic Conference on Computational Methods in Structural Dynamics and Earthquake Engineering M. Papadrakakis, M. Fragiadakis (eds.) Streamed from Athens, Greece, 28 - 30 June 2021

\title{
EXPERIMENTAL INVESTIGATION ON ANCHORAGE PERFORMANCE OF EMBEDDED SMOOTH REBARS SUBJECTED TO CYCLICNG LOADING
}

\author{
Anthony Paderno ${ }^{1}$, Simone Pelucco ${ }^{1}$, and Marco Preti ${ }^{1}$ \\ ${ }^{1}$ University of Brescia, D.I.C.A.T.A.M. \\ via Branze 43, 25123, Brescia (BS), Italy \\ e-mail: a.paderno007@unibs.it \\ s.pelucco@unibs.it \\ marco.preti@unibs.it
}

\begin{abstract}
The most of the reinforced concrete frame structures of the European building stock have been built without attention to the seismic action or according to obsolete code. Before the 1970's, in all the Mediterranean area, plain rebars were employed for the longitudinal reinforcement of structural members. Due to their smooth surface, they are characterized by poor bond capacity; this results in a significant slip of the loaded bar from the surrounding concrete, which strongly increases the structural deformation capacity compared to modern ribbed rebars. Whereas the cyclic response of non-conforming reinforced concrete members and structural sub-assemblies is deeply investigated in literature, a scarce knowledge about anchored plain bar cyclic behaviour is noticed. In the recent years, detailed non-linear modelling of gravity load designed structures is widely used for the seismic vulnerability assessment; a deep investigation on full scale anchorage detailing is then fundamental for the correct modelling of such structures.

In the present paper an experimental investigation on different anchorage solution of plain rebar embedded in concrete is presented; straight, hook-ended and $45^{\circ}$ bent rebar were analysed, monitoring their axial stress versus slip behaviour. A non-linear stress-slip behaviour was observed for all the anchorage solutions since the lower loading level. Stiffness degradation due to cyclic loading was observed; on the other hand, strength decay was visible only for straight anchorage length. Hook-end device and bar bent resulted effective in providing a good anchorage performance, on the other hand their response showed a progressive plasticization.
\end{abstract}

Keywords: Existing RC Buildings, Plain reinforcement, Bar Slip, Experimental Test, Cyclic behaviour, rebar anchorage. 


\section{INTRODUCTION}

The Reinforced Concrete (RC) structures built from the World War II to the 1970's are significantly vulnerable against the seismic action [1]-[3]. Lack in the structural organization and in the seismic detailing, design according to obsolete codes, and interaction with structural or non-structural stiff elements are the main reasons of not adequate structural response. Moreover, smooth bars were used until the seventies as reinforcement in RC frame members.

The poor bond capacities of plain reinforcement influence the structural response since they are related to significant bar slip from the concrete embedment [4]-[8]. The main mechanisms governing the bond strength are: i) the chemical adhesion between the smooth rebar and the surrounding concrete and ii) the micro-interlocking due to concrete small particles wedging action [9]. These contributions bring to a peak bond strength value, after which the slip triggering causes a progressive degradation of the bond capacity [10]. Micro-interlocking and frictional resource reduce also under cyclic loading, like clearly shown by experimental tests on a short anchorage length [11]. Moreover, beyond the reinforcement yielding, a gradual reduction of the rebar transversal section (due to Poisson effect) causes a further loss of strength [9], [12]. Rebar straight length cannot be enough to guarantee an effective anchorage; end hooked and/or bent bar are so employed to improve the anchorage performance. In this case the bar slip depends also on the plastic deformation related its straightening, which is required for the slip development. Pull-out tests on straight smooth rebars of short anchorage length are available in the literature [11], [13], [14]; however, only one of them [11] investigates the effect of a cyclic loading. A $80 \mathrm{~cm}$ hollow square cross section bar was also tested under pull-out force [14], showing that bond stress profile significantly varies along the bar length; more in detail, the peak bond strength is shifted inward under the increase of the axial stress.

In the present work an experimental campaign is described, aimed at clarifying some of the cited aspects. Straight long length anchorage, hook-end and bent rebars are considered. Their axial stress-slip behaviour was analysed, both before and beyond the bar yielding. In the following, the experimental campaign is described, with reference to the different specimen geometry and to the adopted loading protocol. The experimental results are then presented and discussed, paying attention to the different performances related to the investigated anchorage arrangement. The analysis of the stress-slip behaviour of smooth rebar is fundamental for the assessment of the deformation capacities of existing RC member in presence of seismic loading. Indeed, previous experimental tests on columns [11], [15]-[17], beams [18], and beam-column joints [4], [5], [8], [19] showed the great influence of plain reinforcement slip in the definition of the crack pattern and in ensuring a significant flexural deformation capacity. The same results can be also useful for the definition and the validation of analytical or numerical modelling which explicitly account for the bar slip phenomenon.

\section{DESCRIPTION OF THE SPECIMENS}

The reference specimens are schematized in Figure 1. For testing convenience, they are organized so as one or two anchored rebars are embedded in a concrete block; when two bars are placed in the same block, they were tested separately and they were casted at sufficient distance to avoid interference between the two tests. The same choice also allows to investigate different bond conditions effects; indeed, it is possible to qualitatively consider the lower and the upper bar as being in good and bad bond condition, respectively. No transversal reinforcement is provided since possible brittle failures were not expected, due to the adopted geometry.

A straight rebar, with no end specific detailing, characterizes the so-called SL specimens. They are designed to allow the investigation of the bond performance over a significant rebar length, on which it is expect a non-constant bond stress distribution. A total number of four 
specimens were casted; two of them are instrumented with three couples of strain-gauge, with the aim of measuring the axial stress on the embedded length. A reduced adherent length is thus guaranteed in this case, due to the introduction of a local cage to protect the strain gauges around the bar at the gauge location. The specific anchorage type is representative of the bar embedment into column or beam lengths. The hook-end specimens ( $\mathrm{H}$ type) are representative of the T-column-beam joint reinforcement anchorage and of columns rebar anchorage at any cold joint. Four out of six hook-ended bar specimens are characterized by adherent straight length (prior to the hook device); in the other two, bond in the same length is prevented a plastic pipe surrounding the bar. Finally, $45^{\circ}$ bent rebars (B type) were tested; they were frequently used in construction practice for the beam reinforcement over the supports. To monitor the axial stress along the rebar length, two bent bars (casted in the same concrete block) are instrumented with two couple of strain gauges, respectively placed at mid-way of the inclined length and in the last straight length; a steel plate is welded on the bar end, to allow the stress reading by the end gauges couple.

\subsection{Geometry}

$12 \mathrm{~mm}$ diameter reinforcing bars are considered; a minimum concrete cover of $100 \mathrm{~mm}$ and a bar distance of $250 \mathrm{~mm}$ or $450 \mathrm{~mm}$ are guaranteed (respectively for the $\mathrm{H}$ and B types). SL samples are made by a concrete block with $200 \mathrm{~mm}$ square cross section and a length of $1000 \mathrm{~mm}$, in which a single bar is embedded; two out of four specimens (called SL3 and SL4 in the following) are characterized by a lower $760 \mathrm{~mm}$ embedded length, due to strain gauges application along the rebar length (Figure 3). The $\mathrm{H}$ sample bar geometry is referred to the Italian Code indications [20]. A 40 diameter $(480 \mathrm{~mm})$ straight length precedes the hook device, which is characterized by an inner bending of 5 diameters $(60 \mathrm{~mm})$ amplitude and a 3 diameters $(36 \mathrm{~mm})$ final straight length. The four bars with embedded straight length are called $\mathrm{H} 1$ and $\mathrm{H} 2$, the other two H3. The B specimens are characterized by a $120 \mathrm{~mm}$ long embedded straight lengths at the bar ends; their axes distance $450 \mathrm{~mm}$ in the vertical direction, the $45^{\circ}$ inclined length is thus $537 \mathrm{~mm}$ long. The inner radius of the bending is equal to 10 diameters $(120 \mathrm{~mm})$. The two instrumented rebars are called B2.

\subsection{Load frame}

The self-balanced steel frame schematized in Figure 2 is used to impose the bar slip. A $3.5 \mathrm{~mm}$ thread loading screw of $32 \mathrm{~mm}$ diameter allows a continuous refined control of the displacement imposition. Both tensile and compressive load can be applied to the rebar, thanks to the reaction guaranteed by two steel pates; one is in contact with the concrete block head, the other one on the opposite concrete block end. These reaction plates are connected by four threaded bars, lightly prestressed to avoid relative movements.

The smooth rebar sample is anchored to the frame by means of a mechanical joint made of an hollow cylinder in which three high hardness steel screws punch the rebar surface. The rebar head-joint is fixed to a load cell; the latter is then connected by a torsion-free joint to the loading screw. The frame weight and loading torque are transmitted by the steel plates on external supports. 


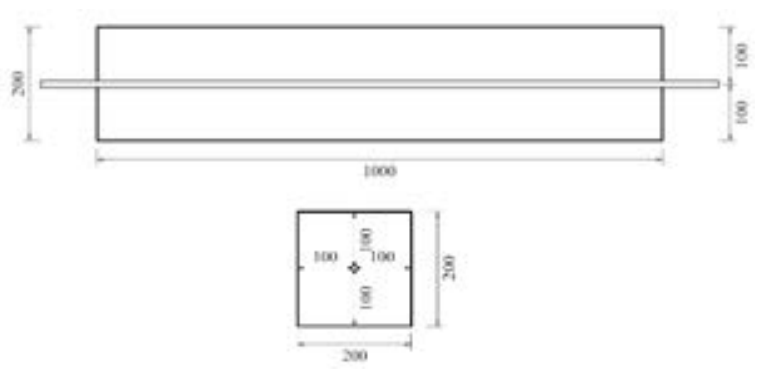

SL Sample

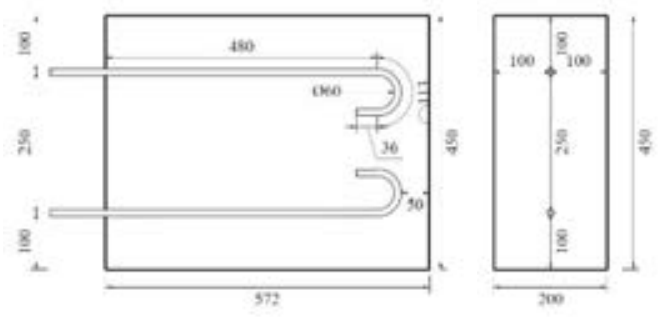

H Sample

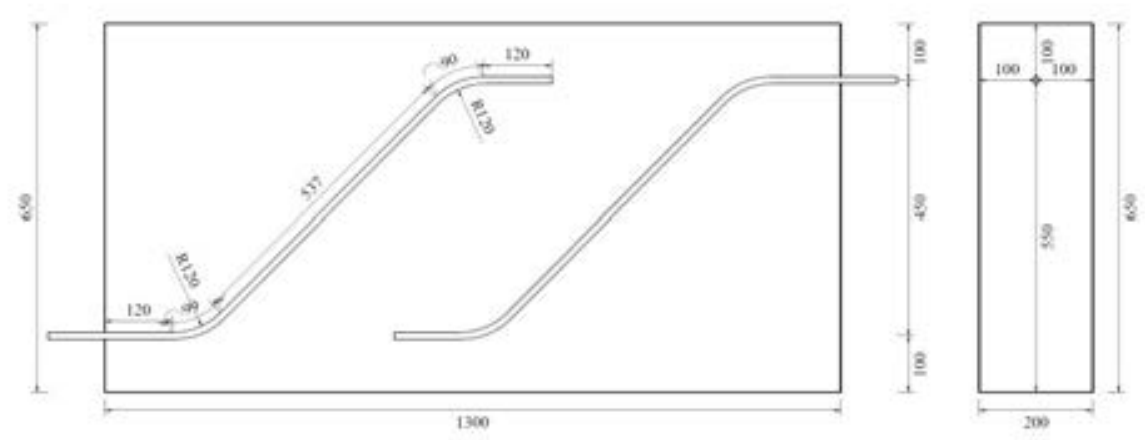

B Sample

Figure 1 Geometry of the tested specimens.

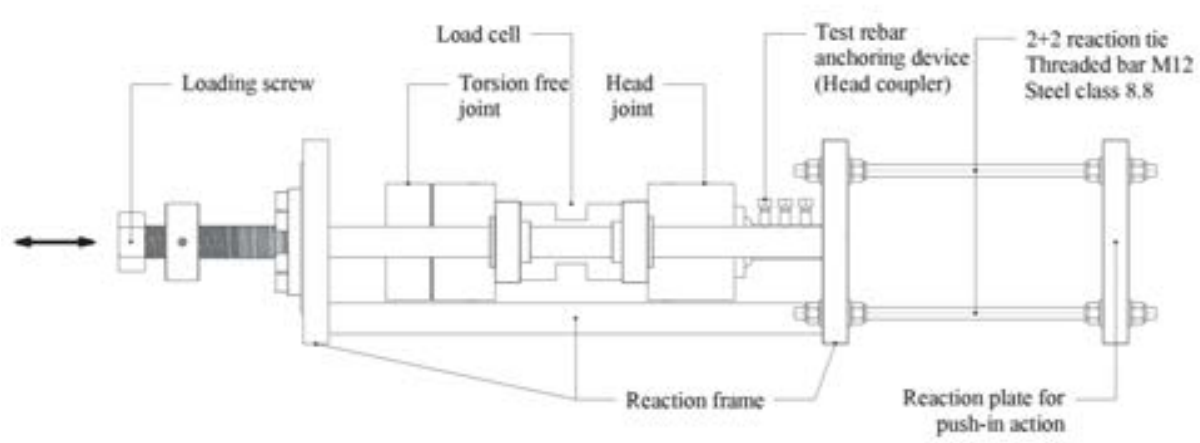

Figure 2 Schematic representation of the load frame.

\subsection{Materials}

Hot rolled reinforcing steel of grade S275 JR is considered [21]. Yielding, $f_{y}$, and failure, $f_{u}$, stress were investigated by a tensile test according to [22]; they were significantly different for the straight length (SL samples) bars and for the shaped (H and B samples) ones. Also the total elongation on a 10-diameter reference length across the failure section $\Delta \mathrm{L}$ is defined.

The reference concrete mix design was the same for all the samples. Since they were casted in different times, the average compressive strength, $\mathrm{f}_{\mathrm{c}}$, and the elastic modulus, $\mathrm{E}_{\mathrm{c}}$, are defined 
for each specimen type. The results are reported in Table 1 in terms of mean values; they are representative of the properties of the material employed in the reference $\mathrm{RC}$ frame construction.

\begin{tabular}{llllll}
\hline $\begin{array}{l}\text { Sample } \\
\text { type }\end{array}$ & Steel & \multicolumn{3}{c}{ Concrete } \\
\cline { 2 - 6 } $\mathrm{f}_{\mathrm{y}}[\mathrm{MPa}]$ & $\mathrm{f}_{\mathrm{u}}[\mathrm{MPa}]$ & $\Delta \mathrm{L}$ & $\mathrm{f}_{\mathrm{c}}[\mathrm{MPa}]$ & $\mathrm{E}_{\mathrm{c}}[\mathrm{MPa}]$ \\
\hline SL & 442 & 535 & 13.70 & 24.71 & 25490 \\
$\mathrm{H}$ & 361 & 519 & 20.16 & 19.53 & 22810 \\
$\mathrm{~B}$ & 363 & 520 & 18.98 & 22.52 & 25175 \\
\hline
\end{tabular}

Table 1 Mean values of the mechanical properties of the employed materials.

\section{INSTRUMENTATION AND LOADING PROTOCOL}

\subsection{Instrumentation}

Load and displacement transducers are used to measure the bar axial stress-slip behaviour. Three different LVDTs are concentrically placed around the rebar head; they measure the displacement between the load frame head joint and the concrete block. A supplemental LVDT monitored the slip of the bar tail in SL specimens. The load cell is placed in the load frame, as it is schematized in Figure 2.

Strain-gauges are used to measure the axial strain along the rebar embedded length. An $80 \mathrm{~mm}$ length is deactivated around the extensimeter, to protect the gauges and avoid bond interference; the simplified representation of the arrangement is shown in Figure 3. On straight bars (SL3 and SL4) they are placed with a spacing of $250 \mathrm{~mm}$, therefore three different cross section are monitored. On bent rebars they are placed at midway of the inclined length and in the straight tail end. In this case, a mechanical anchorage is guaranteed after the last gauges, to allow a stress reading; indeed, no embedded length is present beyond the gauge deactivated length.

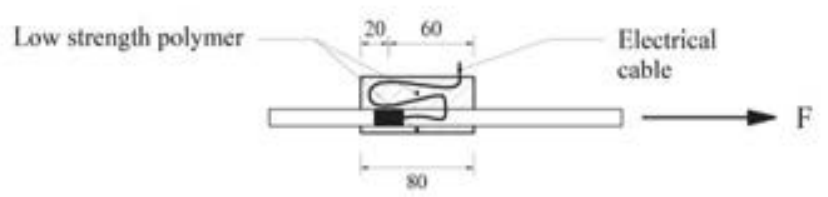

Figure 3 Detailing of the strain gauge isolation from the surrounding concrete.

\subsection{Loading protocol}

The straight rebars are tested in slip control during all the test. On the other hand, the shaped bars are load-controlled below the yielding point and slip-controlled beyond it. A summary of the reference loading protocol is visible in Figure 4.

The unloading phase was always characterized by the recovering of all the imposed slip; thus, also compressive loads were imposed to the rebar. For the $\mathrm{H}$ specimens in which the straight length was not adherent to the concrete, the unloading is stopped at the null force point since the application of compression to the rebar triggered its buckling. 

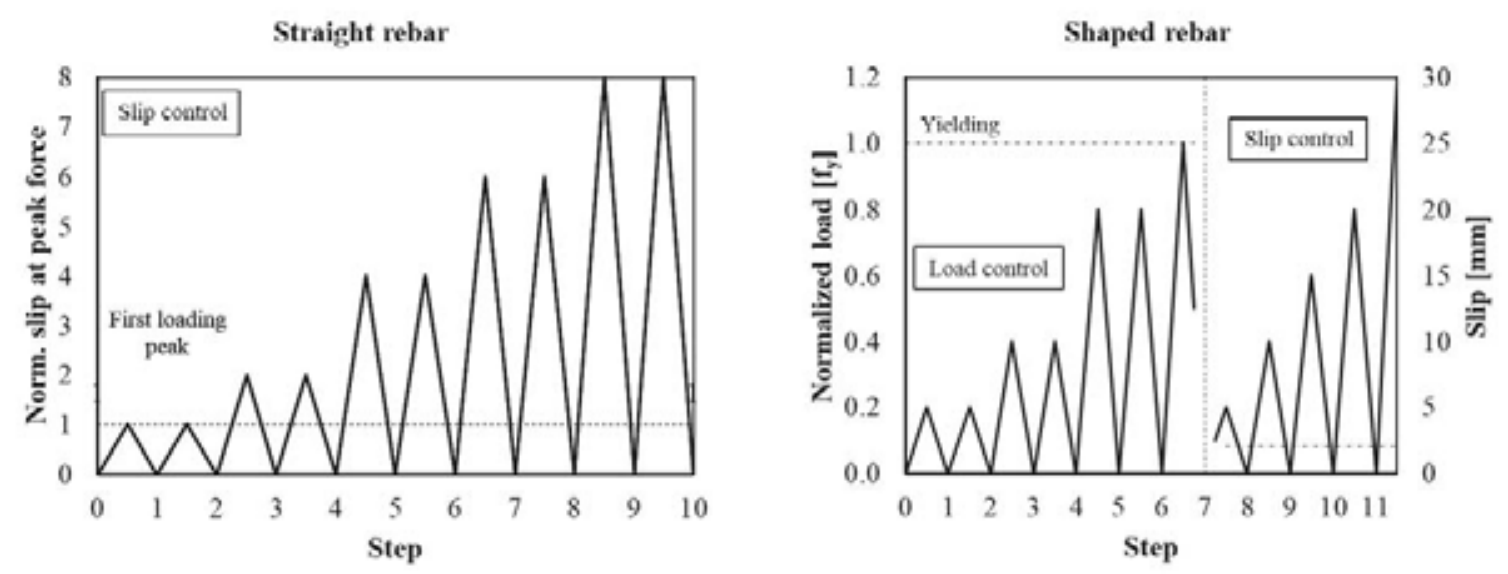

Figure 4 Loading protocol schematization for straight and shaped rebars.

\section{EXPERIMENTAL RESULTS}

\subsection{Straight bar}

The experimental results of the four tested rebars are divided according to the total embedded length (Figure 5). SL1 and SL2 samples are adherent to concrete along all the specimen length (1000mm); on the other hand, SL3 and SL4 samples are embedded for $760 \mathrm{~mm}$, due to strain gauge application along their length. The former showed the capacity in anchoring the bar yielding, whereas the latter showed a strength decay at a force lower than yielding. Nevertheless, the strength degradation is observed after the triggering of the bar tail slip in both the case. After the reach of the peak force, the cyclic behaviour is controlled by a lower strength. A reloading force can be observed exploring new slip of larger amplitude; cycling at a target deformation level, a residual lower strength is instead noticed. Subsequent cycles and slip amplitude within the range previously explored seemed not to influence the reference strength capacities.
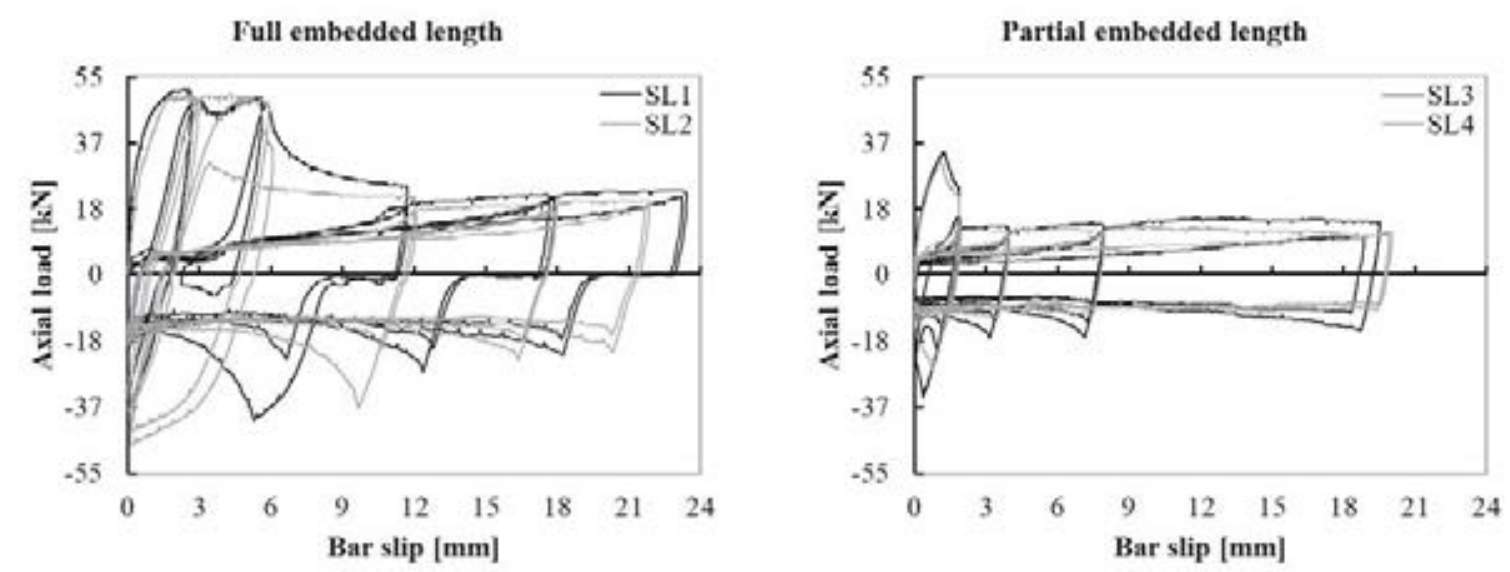

Figure 5 Stress-slip behaviour of the SL-type specimens: full and partial embedded length samples response.

\subsection{Hook-end bar}

In the following the bottom bars of the $\mathrm{H}$ specimens are qualitatively identified as being in good bond condition, whereas the top ones are considered in bad bond conditions. In Figure 6 the response of two different concrete specimens ( $\mathrm{H} 1$ and $\mathrm{H} 2)$ is represented up to the reach of 
the bar yielding. A non-linear elastic loading branch was followed by a plastic plateau. The cyclic behaviour was characterized by a linear force-slip relationship, stiffer for the unloading and secant during the reloading (oriented to the maximum explored slip point at the previous cycle). Significant difference in the elastic stiffness is noticed with respect to the identified bond conditions. The unloading stiffness is not influenced in subsequent cycles and by the explored drift level; it is higher than the secant value at the yielding point. Good anchoring performance was observed also in presence of compressive loads; moreover, a less stiff behaviour is noticed at the load reversal.

In presence of unbonded straight length (H3 specimens), the behaviour was similar (Figure 7); however, a less stiff loading can be observed. In this case the bond conditions seemed not to affect the force-slip relationship. It is possible to conclude that the hook device alone can provide the bar anchorage; it is effective also in ensuring the bar overstrength (hardening behaviour). This is clearly is visible in Figure 7, where the complete response of the upper bar of the concrete block H3 is represented up to a slip magnitude of $45 \mathrm{~mm}$.
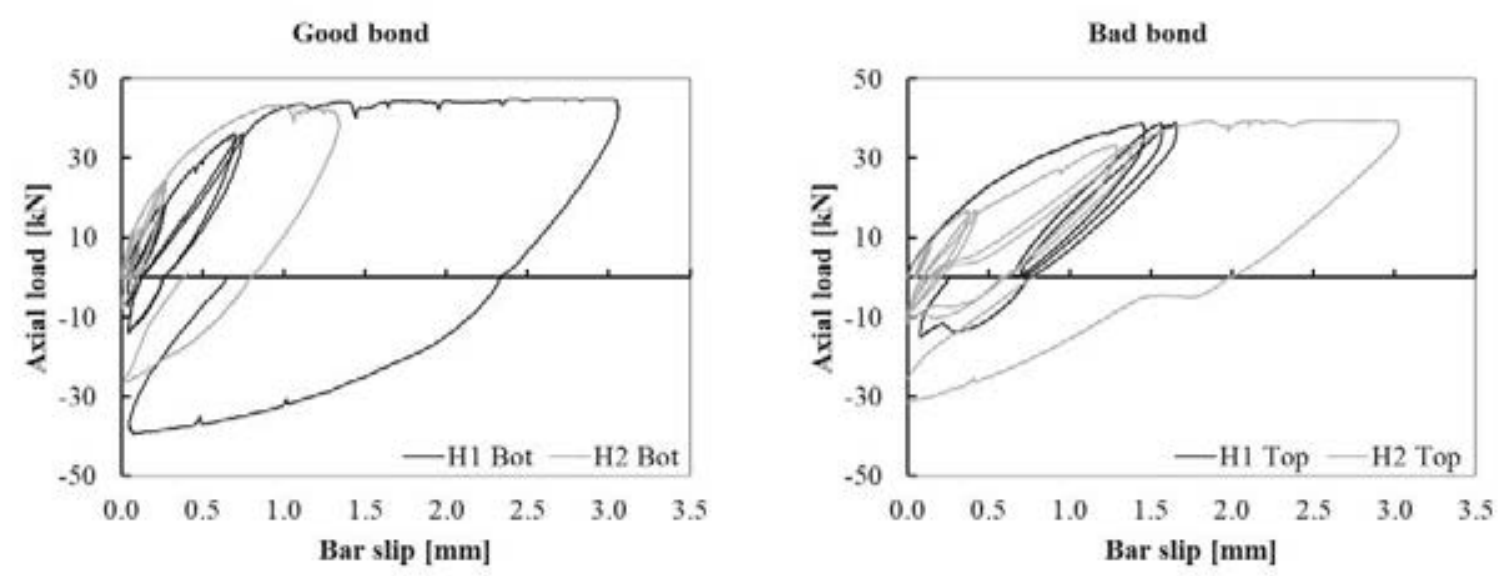

Figure 6 Experimental response of $\mathrm{H} 1$ and H2 samples: lower (good bond) and upper (bad bond) tested rebar responses.
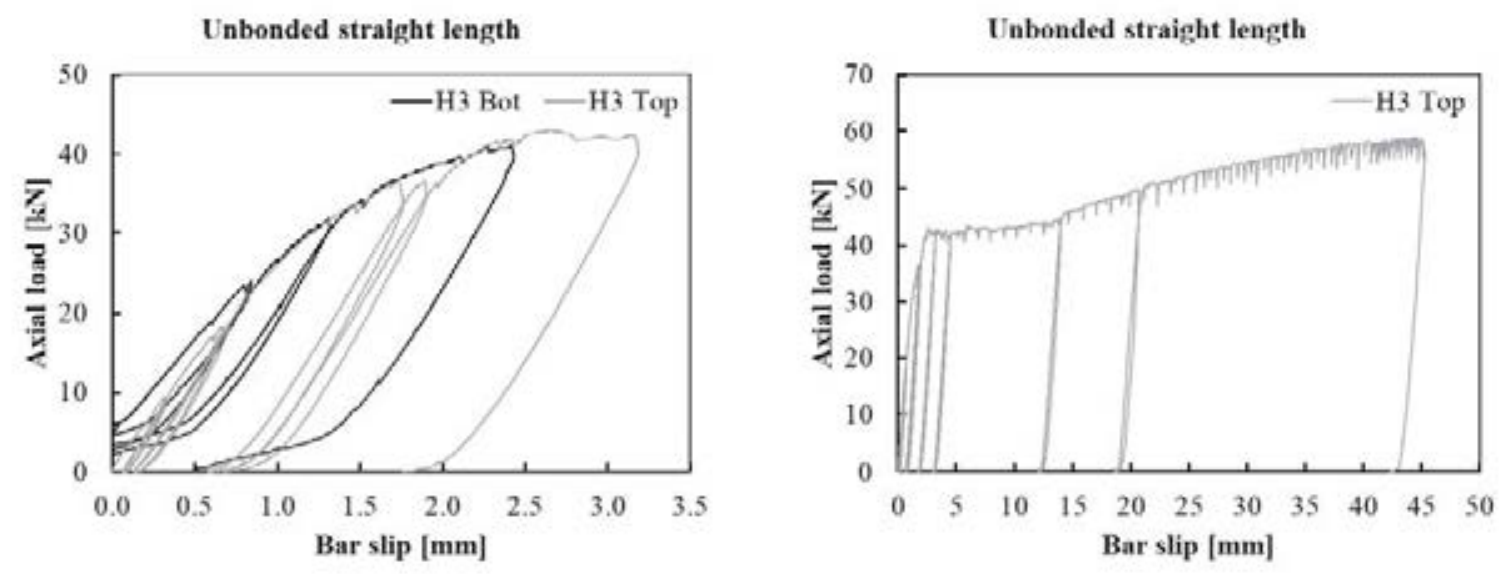

Figure 7 Cyclic response of $\mathrm{H} 3$ sample rebars: focus on the elastic cycles and complete response of the upper bar. 


\subsection{Bent rebar}

Since the B type rebars cross the concrete block from top to bottom, and vice versa, in the following good or bad bond conditions refer to the bar head position (end on which the load was applied). The response of the bent rebars (Figure 8) was very close to the one of the hookended bars, especially in good bond conditions. The cycles in the range of the elastic stress were enveloped by a non-linear stress-slip relationship, after which a plastic plateau took place. The bending of the rebar ensures the anchorage of the bar up to yielding stress, and more, including overstrength (the graphs of Figure 8 are cut at the cycles of yielding). Only the instrumented bar (B2 sample) showed difference stress-slip response before yielding (bad bond condition); indeed it was more deformable.

The bars in bad bond conditions showed an increasing stiffness gradient (concave stress-slip curve) before yielding. This behaviour was associated with an initial sliding of the rebar, which was confirmed by a strain reading in both the strain gauge placed on the instrumented rebar in bad bond condition.
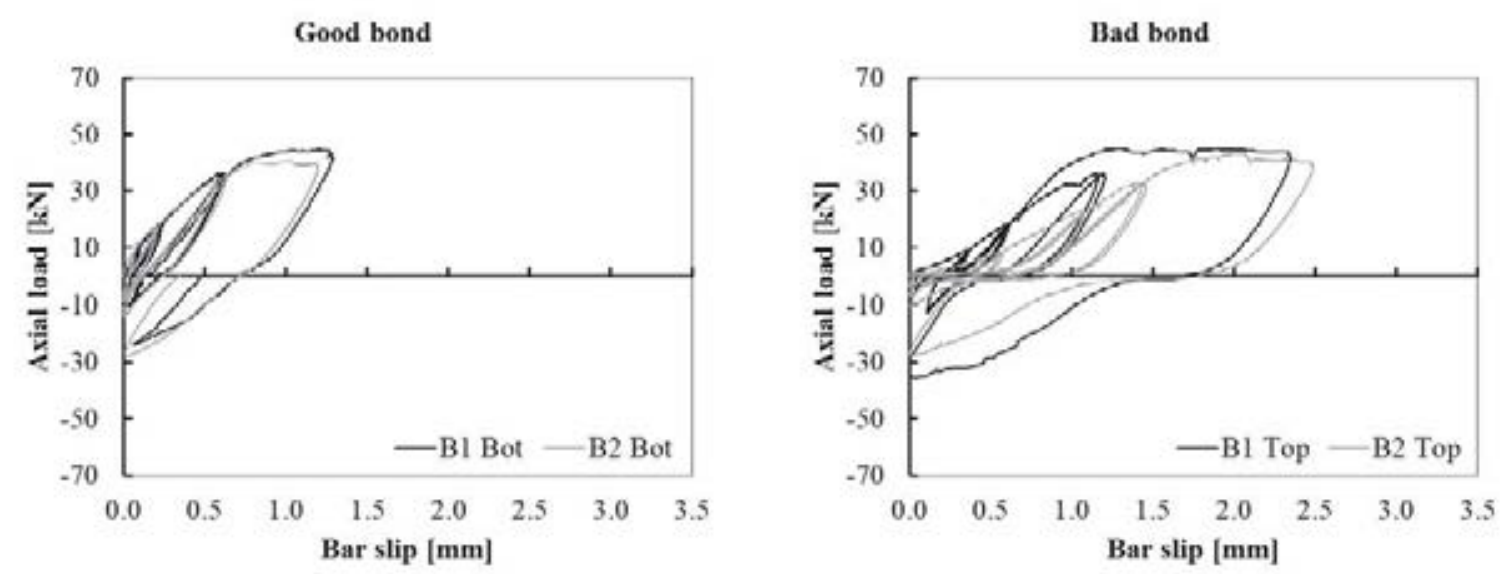

Figure 8 Stress-slip behaviour of bent rebars under cyclic loading up to the yielding point.

\section{RESULTS COMPARISON}

\subsection{Straight length anchorage}

To evaluate the anchorage performance of a straight bar, an average constant bond stress distribution along the rebar embedded length is considered, as suggested in literature. With reference to experimental measure of i) peak, ii) reloading, and iii) residual forces, the calculated bond capacities are reported in Table 2.

To help the comparison of the experimental evidences with literature available models, a normalization of the bond strength $\tau_{b}$ over the concrete compressive strength is taken:

$$
\tau_{b}=C \sqrt{f_{c}}
$$

with $\mathrm{C}$ non dimensional coefficient and $f_{c}$ mean cylindrical concrete compressive strength. The values reported in Table 2 are lower with respect to the literature available model in term of peak force [11]-[13], [15]. On the other hand, the reloading and residual capacities well match with the available indications [11], [15]. 


\begin{tabular}{lllllll}
\hline \multirow{2}{*}{ Sample } & \multicolumn{2}{l}{ Peak strength } & \multicolumn{2}{l}{ Reloading strength } & \multicolumn{2}{l}{ Residual strength } \\
\cline { 2 - 7 } & Force $[\mathrm{kN}]$ & Bond $[\mathrm{MPa}]$ & Force $[\mathrm{kN}]$ & Bond $[\mathrm{MPa}]$ & Force $[\mathrm{kN}]$ & Bond [MPa] \\
\hline SL1 & 51 & 1.36 & 22 & 0.58 & 12 & 0.32 \\
SL2 & 50 & 1.33 & 19 & 0.50 & 12 & 0.32 \\
SL3 & 34 & 1.18 & 15 & 0.52 & 6 & 0.28 \\
SL4 & 31 & 1.09 & 12 & 0.42 & 8 & 0.21 \\
\multirow{2}{*}{ Mean } & Bond $[\mathrm{kN}]$ & 1.24 & Bond $[\mathrm{kN}]$ & 0.51 & Bond $[\mathrm{kN}]$ & 0.28 \\
& C & 0.25 & C & 0.10 & C & 0.06 \\
\hline
\end{tabular}

Table 2 Estimation of the anchorage capacity along a straight rebar in hypothesis of constant bond stress.

\subsection{Shaped anchorage}

The difference in stiffness between the response of bars anchored in good or bad bond conditions is clearly visible by the observation of the graphs in Figure 9. The cyclic response below the yielding point is plot for all the shaped anchored rebars tested; it makes exception the $\mathrm{H} 3$ block bars, whose response was not affected by bond conditions. The stiffer behaviour showed the reach of the bar yielding at a slip level lower than $0.75 \mathrm{~mm}$; on the other hand, the less stiff response showed the yielding reach at a slip magnitude of about $1.50 \mathrm{~mm}$. Therefore, two different values of the secant stiffness at yielding can be attributed to the bars in good bond conditions. Moreover, the response in good bond conditions is very similar both for hooked or bent shape. On the other hand, in bad bond conditions the stress-slip relationships of the different anchorage solutions is strong; nevertheless, the secant stiffness at yielding is similar.
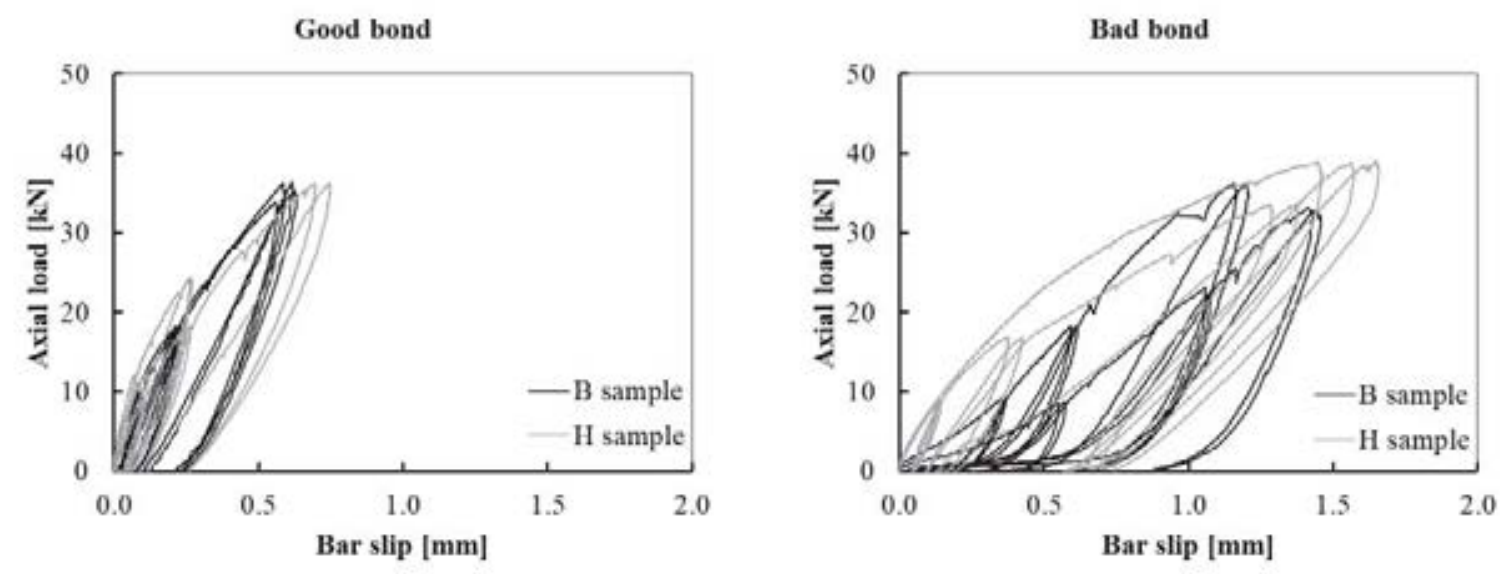

Figure 9 Focus on the elastic response of hooked (grey lines) and bent (black lines) rebars.

\section{CONCLUSIONS}

The experimental cyclic response of different anchorage solutions for smooth rebar is herein investigated. Long straight anchorage length, hook-end device, and bar bent were tested in presence of both tensile and compressive loads. The response, in term of force versus slip relationship, was monitored and it is herein discussed.

The straight length anchorage gave equilibrium to different applied force values, depending on its overall embedded length; in presence of the lower anchorage length $(760 \mathrm{~mm})$ a peak strength about the $60 \%$ of the bar yielding stress was reached. In all the cases, at the triggering of the last embedded section slip, a force degradation was observed. Exploring higher slip level, a reloading bond strength can be defined, while cycling in the same slip range (of previously explored cycles) a lower residual strength was observed. Hook-end device and bar bent were 
effective in ensuring the bar yielding and overstrength force. No force degradation was observed, and the response was stable, also at the highest slip imposition. The position of the shaped rebar with respect to the concrete block sample significantly influenced the stiffness of the response; the lower (good bond condition) bars reached the yielding point at slip level lower than $0.75 \mathrm{~mm}$, the top ones (bad bond condition) at a value of deformation twice. The unloading of the shaped anchorages showed a residual plastic deformation, also cycling at stress values lower than the yielding one. Since a straightening is required for the bar pullout under tensile force, plastic deformations are expected in the hook (or bending) length; moreover, the same straightening causes high local stress in the surrounding concrete. The different concrete porosity can affect the anchorage slip development, justifying the difference herein presented between the anchorage response in good or bad bond conditions. This aspect will be considered in future studies.

\section{ACKNOWLEDGEMENT}

The experimental campaign presented in this work has been supported within the framework of DPC/ReLUIS project 2019-2021, WP5.

\section{REFERENCES}

[1] L. D. Decanini, A. De Sortis, A. Goretti, L. Liberatore, F. Mollaioli, and P. Bazzurro, 'Performance of Reinforced Concrete Buildings during the 2002 Molise, Italy, Earthquake', Earthquake Spectra, vol. 20, no. 1_suppl, pp. 221-255, 2004a, doi: 10.1193/1.1765107.

[2] C. Del Gaudio et al., 'Empirical Fragility Curves From Damage Data on RC Buildings After the 2009 L'Aquila Earthquake', Bull Earthquake Eng, vol. 15, no. 4, pp. 14251450, Apr. 2017, doi: 10.1007/s10518-016-0026-1.

[3] G. M. Verderame, I. Iervolino, and P. Ricci, 'Report on the Damages on Buildings Following the Seismic Event of 6th of April 2009 Time 1.32 (UTC) - L'Aquila M=5.8', p. 17, 2009c.

[4] C. Beschi, P. Riva, G. Metelli, and A. Meda, 'HPFRC Jacketing of Non Seismically Detailed RC Corner Joints', Journal of Earthquake Engineering, vol. 19, no. 1, pp. 25-47, Jan. 2015, doi: 10.1080/13632469.2014.948646.

[5] F. Braga, R. Gigliotti, and M. Laterza, 'R/C Existing Structures with Smooth Reinforcing Bars: Experimental Behaviour of Beam-Column Joints Subject to Cyclic Lateral Loads', TOBCTJ, vol. 3, no. 1, pp. 52-67, May 2009, doi: $10.2174 / 1874836800903010052$.

[6] G. M. Calvi, G. Magenes, and S. Pampanin, 'Experimental Test on a Three Storey RC Frame Designed for Gravity Only', Proceedings of 12th European Conference on Earthquake Engineering, p. 8, 2002.

[7] S. Pampanin, G. M. Calvi, and M. Moratti, 'Seismic Behaviour of RC Beam-Column Joints Designed for Gravity Loads', p. 11, 2002.

[8] G. Russo and M. Pauletta, 'Seismic Behavior of Exterior Beam-Column Connections with Plain Bars and Effects of Upgrade', SJ, vol. 109, no. 2, 2012, doi: $10.14359 / 51683633$. 
[9] L. Feldman and M. Bartlett, 'Bond Strength Variability in Pullout Specimens with Plain Reinforcement', ACI Structural Journal, no. 102, 2005.

[10] M. F. Stocker and M. A. Sozen, 'Investigation of Prestressed Reinfroced Concrete for Highway Bridges - Part VI: Bond of Prestressing Strand'. 1969.

[11] G. M. Verderame, P. Ricci, G. D. Carlo, and G. Manfredi, 'Cyclic Bond Behaviour of Plain Bars. Part I: Experimental Investigation', Construction and Building Materials, vol. 23, no. 12, pp. 3499-3511, Dec. 2009, doi: 10.1016/j.conbuildmat.2009.07.002.

[12] Model Code, 'Model Code for Concrete Structures 2010 fib - International Federation for Structural Concrete)'. Ernst \& Sohn, Berlin, Germany, 2010.

[13] G. Fabbrocino, G. M. Verderame, and G. Manfredi, 'Experimental behaviour of anchored smooth rebars in old type reinforced concrete buildings', Engineering Structures, vol. 27, no. 10, pp. 1575-1585, Aug. 2005, doi: 10.1016/j.engstruct.2005.05.002.

[14] L. Feldman and M. Bartlett, 'Bond Stresses Along Plain Steel Reinforcing Bars in Pullout Specimens', ACI Structural Journal, vol. 104, no. 6, pp. 685-692, 2007.

[15] G. M. Verderame, G. De Carlo, P. Ricci, and G. Fabbrocino, 'Cyclic Bond Behaviour of Plain Bars. Part II: Analytical Investigation', Construction and Building Materials, vol. 23, no. 12, pp. 3512-3522, Dec. 2009, doi: 10.1016/j.conbuildmat.2009.07.001.

[16] M. Di Ludovico, G. M. Verderame, A. Prota, G. Manfredi, and E. Cosenza, 'Experimental Behavior of Nonconforming RC Columns with Plain Bars under Constant Axial Load and Biaxial Bending', J. Struct. Eng., vol. 139, no. 6, pp. 897-914, Jun. 2013, doi: 10.1061/(ASCE)ST.1943-541X.0000703.

[17] J. Melo, H. Varum, and T. Rossetto, 'Experimental Cyclic Behaviour of RC Columns with Plain Bars and Proposal for Eurocode 8 Formula Improvement', Engineering Structures, vol. 88, pp. 22-36, Apr. 2015, doi: 10.1016/j.engstruct.2015.01.033.

[18] M. S. Marefat, S. M. Hassanzadeh Shirazi, R. Rostamshirazi, and M. Khanmohammadi, 'Cyclic Response of Concrete Beams Reinforced by Plain Bars', Journal of Earthquake Engineering, vol. 13, no. 4, pp. 463-481, May 2009, doi: 10.1080/13632460902837769.

[19] S. Pampanin, G. M. Calvi, and M. Moratti, 'Seismic Behaviour of RC Beam-Column Joints Designed for Gravity Loads', p. 10, 2002.

[20] RD 2229, 'Regio Decreto n.2229 del 19 Novembre 1939 (in italian)'. 1939.

[21] EN 10025, 'Hot Rolled products of structural steels'. 2019.

[22] UNI EN 10080, 'UNI EN 10080 Steel for the Reinforcement of Concrete - Weldable Reinforcing Steel'. 2005. 